Iryna Koretska,

$\mathrm{PhD}$ in Technical Sciences, Associate Professor National University of Food Technologies 68, Volodymirska, str., Kyiv, 01601, Ukraine

ORCID: 0000-0001-5680-5789

ResearcherID: D-7808-2019

Liudmyla Deinychenko, $\mathrm{PhD}$ in Technical Sciences

National University of Food Technologies 68, Volodymirska, str., Kyiv, 01601, Ukraine

ORCID: 0000-0002-9641-2266

ResearcherID: AAH-2602-2020

Tamara Kravchenko,

$\mathrm{PhD}$ in Pedagogic Sciences, Associate Professor Uman State Pedagogical University named after Pavlo Tychyna 2, Sadova str., Uman, 20300, Ukraine ORCID: 0000-0002-3512-8624

ResearcherID: E-4778-2019

\title{
ANALYSIS OF THE NONLINEAR CRITERIA USE FOR THE FOODS QUALITY ASSESSMENT
}

The article presents an analysis of the use of nonlinear criteria definition for the foods quality checking. Comparative calculations of the main organoleptic indicators of foods, as well as their descriptors, showed identical results. The possibility of use the calculation of both the qualimetric quality criteria and the calculation of the quality criteria by profilograms when determining the priority of samples is proved.

Keywords: foods, quality analysis, priority of samples, rating.

Relevance of research topic. Priority evaluation of foods samples is the process of identifying and taking into account non-influential factors and determining or predicting the place of a particular food product on the market. Also, one of the study aspects is the analysis of current ways of foods evaluating by certain sensory indicators that can attract a potential consumer and promote the product.

Today, when determining the average (or cumulative) score, several basic areas of sensory analysis are used, in particular, sensory analysis during the implementation of the quality control program, qualitative evaluation of samples, determination of the quality criteria by profilogram $[1,2]$. 
Sensory analysis of the samples of foods is an important task as it is the fastest and easiest way to determine the quality of samples, allowing distinguishing high quality samples from ordinary ones in order to put into production only those samples that will gain the market.

Formulation of the problem. The tasting committee considers the presented samples of foods and makes decisions on recommendations for its implementation at the enterprise. The evaluation of the samples is based on organoleptic indicators by determining the average score and the calculation of the tasting list points, taking into account the descriptors of the main indicators [3]. Important aspects of such evaluation are the collection and subsequent verification of the presented samples by organoleptic parameters and the comparison between similar samples in the experimental group of products. The use of different nonlinear methods for determining the quality criteria will reveal the advantages of the selected methods.

Analysis of recent researches and publications. Many scientific works of domestic and foreign scientists are devoted to the research of foods quality evaluation methods. In particular, on this issue worked Akimova L., Zinchenko V., Kuzmin O., Deinychenko G., Boyko T., Spiteri M., Soler LG. and others [2, 4...6].

But despite considerable theoretical study of the problem, issues related to the processing of information obtained through complex independent evaluation require further scientific development.

Presenting main material. For further calculations, a number of samples of foods developed earlier in the works [7] were selected. A complex of researches was done to create a mathematical model and an optimization decision for the evaluation of this food samples and determining their priority.

During the research, the results of the influence of milk-protein co-precipitates (MPC) on the quality of foods based on cottage cheese were obtained.

To evaluate the samples of presented foods, a 10-point scale of the main organoleptic characteristics of the samples and their descriptors was developed. The sensory characteristics of foods were evaluated in isolation from the influence of such aspects as positioning, packaging, and price.

By combining the indicator lists of each expert, a general list containing all the indicators to be defined in the proposed samples was formed. An accurate verbal description of a specific indicator is developed for each quality level.

The determination of the validity ratio of individual indicators and their descriptors was determined by the Delphi method, the expert method for each group of indicators according to the average values of the descriptors of this group, provided that the sum of the group indicators is 1.0 point.

In order to effectively evaluate the effect of MPC on the organoleptic quality indices of the selected foods, the comparison of the results of different methods of 
quality criteria determination was made. The used methods were the method of calculating the complex indicator of quality (CIQ) and the method of quality criteria definition by profilograms - the «polygon of quality» - which covers a large number of indicators and is sensitive to changes of each of the used criteria.

The chosen foods were evaluated according to the available descriptors and the quality criteria of each sample ware determined (Table 1).

Table 1

Determination of descriptors values by groups of basic organoleptic indicators

\begin{tabular}{|c|c|c|c|c|c|c|c|}
\hline \multirow[b]{2}{*}{ Indicator } & \multirow[b]{2}{*}{ 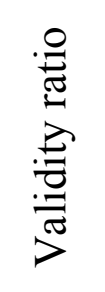 } & \multirow[b]{2}{*}{ 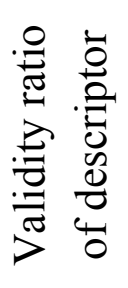 } & \multirow[b]{2}{*}{ Descriptors } & \multicolumn{4}{|c|}{ Samples/ Score in points } \\
\hline & & & & $\begin{array}{c}\text { Curd } \\
\text { fritters } \\
\text { (control } \\
\text { sample) }\end{array}$ & $\begin{array}{l}\text { Curd } \\
\text { fritters } \\
\text { with } \\
\text { MPC }\end{array}$ & $\begin{array}{c}\text { Casserole } \\
\text { (control } \\
\text { sample) }\end{array}$ & $\begin{array}{c}\text { Casserole } \\
\text { with } \\
\text { MPC }\end{array}$ \\
\hline \multirow{2}{*}{ Appearance } & \multirow{2}{*}{0,25} & 0,6 & Attractiveness & 9,90 & 9,88 & 9,60 & 9,72 \\
\hline & & 0,4 & Homogeneity & 9,92 & 9,94 & 9,42 & 9,58 \\
\hline \multicolumn{4}{|c|}{ General score by descriptors } & 9,91 & 9,90 & 9,53 & 9,66 \\
\hline \multicolumn{4}{|c|}{ General score by indicator } & 2,48 & 2,48 & 2,38 & 2,42 \\
\hline \multirow{3}{*}{ Color } & \multirow{3}{*}{0,15} & 0,5 & Evenness & 9,56 & 9,46 & 9,62 & 9,60 \\
\hline & & 0,2 & Intensity & 9,48 & 9,42 & 9,78 & 9,74 \\
\hline & & 0,3 & Naturalness & 9,96 & 9,96 & 9,88 & 9,90 \\
\hline \multicolumn{4}{|c|}{ General score by descriptors } & 9,66 & 9,60 & 9,73 & 9,72 \\
\hline \multicolumn{4}{|c|}{ General score by indicator } & 1,45 & 1,44 & 1,46 & 1,46 \\
\hline \multirow{3}{*}{ Consistency } & \multirow{3}{*}{0,3} & 0,4 & Homogeneity & 9,94 & 9,98 & 9,92 & 9,88 \\
\hline & & 0,2 & Softness & 9,84 & 9,92 & 9,86 & 9,90 \\
\hline & & 0,4 & Whipping & 9,74 & 9,88 & 9,78 & 9,86 \\
\hline \multicolumn{4}{|c|}{ General score by descriptors } & 9,84 & 9,93 & 9,85 & 9,88 \\
\hline \multicolumn{4}{|c|}{ General score by indicator } & 2,95 & 2,98 & 2,96 & 2,96 \\
\hline \multirow{2}{*}{ Smell } & \multirow{2}{*}{0,1} & 0,4 & Distinctiveness & 9,52 & 9,48 & 9,50 & 9,74 \\
\hline & & 0,6 & Purity & 9,64 & 9,70 & 9,62 & 9,60 \\
\hline \multicolumn{4}{|c|}{ General score by descriptors } & 9,59 & 9,61 & 9,57 & 9,66 \\
\hline \multicolumn{4}{|c|}{ General score by indicator } & 0,96 & 0,96 & 0,96 & 0,97 \\
\hline \multirow{3}{*}{ Taste } & \multirow{3}{*}{0,2} & 0,4 & Purity & 9,92 & 9,98 & 9,78 & 9,90 \\
\hline & & 0,2 & Balance & 9,74 & 9,92 & 9,64 & 9,74 \\
\hline & & 0,4 & Naturalness & 9,84 & 9,90 & 9,66 & 9,72 \\
\hline \multicolumn{4}{|c|}{ General score by descriptors } & 9,85 & 9,94 & 9,70 & 9,80 \\
\hline \multicolumn{4}{|c|}{ General score by indicator } & 1,97 & 1,99 & 1,94 & 1,96 \\
\hline
\end{tabular}


An offered 10-point gave more sensitive evaluation of the samples. It was considered that the value of CIQ corresponds to the scores: $K_{0}=10 \ldots 9.0-$ «excellent»; $\mathrm{K}_{0}=7.5 \ldots 8.9-$ «good»; $\mathrm{K}_{0}=5.0 \ldots 7.4-$ «satisfactory»; $\mathrm{K}_{0}=4.9$ and less - «unsatisfactory».

The arithmetic overage value was used to calculate the complex indicator of quality for the samples:

$$
K=\sum_{i=1}^{n} K_{i} \cdot m_{i},
$$

where $K_{i}$ - single indicator score;

$m_{i}$ - validity ratio of descriptor;

$n$ - number of descriptors taken into account.

The final evaluation of a specific indicator of the evaluated foods was determined by obtaining the values of the separate descriptors used to calculate the complex indicators of quality.

The results of the calculations are shown on the Fig. 1.

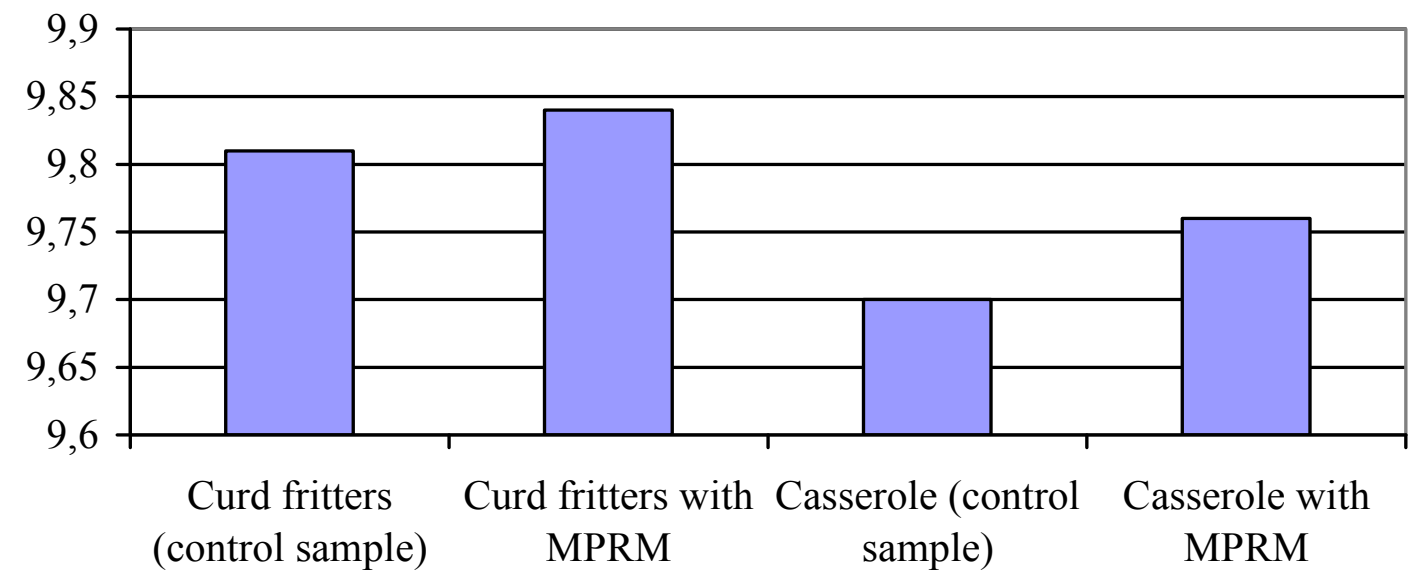

Figure 1. The value of the general qualitative criteria for the quality of food samples (in points)

Analyzing the results obtained, it was found that the samples (according to CIQ) were arranged as follows: in a pair of curd fritters the sample of the dish «Curd fritters with MPC» has 0.03 points more, and in a pair of casseroles the priority of 0.06 points has the dish «Casserole with MPC».

To obtain the quality criteria by the «polygon of quality» method in this mathematical model, previously obtained scores of the studied indicators and their descriptors were used. The most demonstrative is the method of visualizing the foods organoleptic properties in the form of a profilogram, by which it is easy to assess the intensity, severity and difference of descriptors. 
Quality profilograms of separate samples were constructed using the «polygon of quality» method (Figure 2).

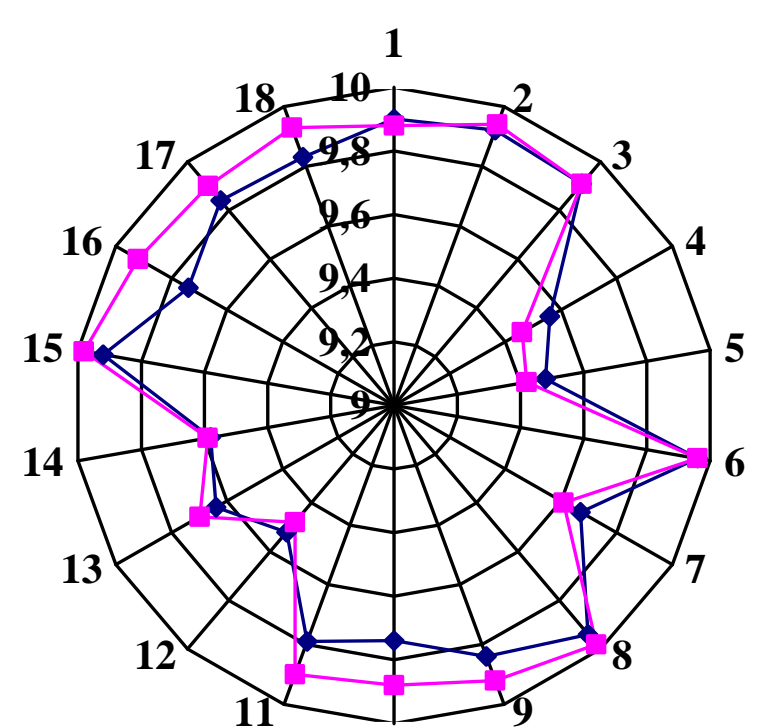

10

$\neg$ Curd fritters (control sample)

$\rightarrow-$ Curd fritters with MPC

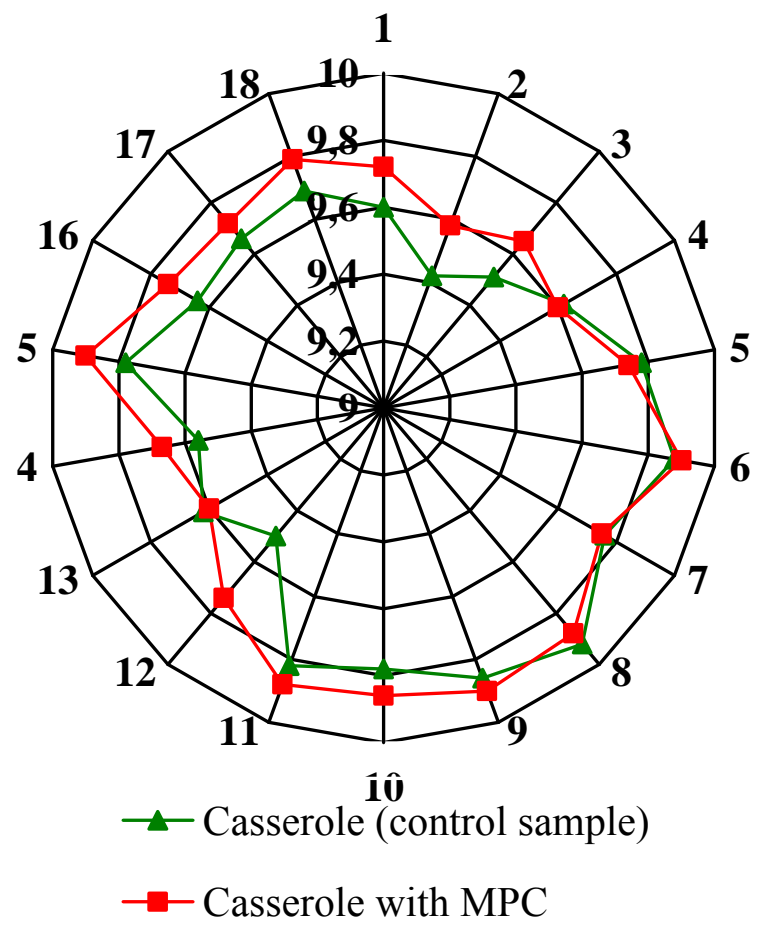

b

Figure 2. Profilograms of sample quality indicators:

$a$-curd fritters; $b$-casseroles. 1 -Appearance; 2 -Attractiveness; 3 - Homogeneity; 4 -Color; 5 -Evenness; 6 - Intensity; 7 - Naturalness; 8 -Consistency; 9 - Homogeneity;

10 - Softness; 11 -Whipping; 12 -Smell; 13 -Distinctiveness; 14 -Purity; 15 -Taste; 16-Purity; 17 -Balance; 18 -Naturalness

The evaluation of the samples by the organoleptic quality indicators of foods was performed using the criteria in the form of the sum of multiplications of the component indices $f_{j}$. Comparison of the samples is possible by using the quality criteria (the area of the represented polygon), which is calculated as the sum of the areas of the individual triangles formed by the rays of the individual quality indicators with the central angle $2 \pi / N$ :

$$
S=\sum_{j=1}^{N}\left(\frac{1}{2} \cdot f_{j} \cdot f_{j+1} \cdot \sin \frac{2 \pi}{N}\right), \quad \text { de } \quad f_{N+1}=f_{1} .
$$

where $f_{\mathrm{i}}$ - the value of a separate indicator, points;

$N$ - number of samples. 
Based on the evaluation results quality criteria $\left(S^{2}\right.$, points) were calculated for the samples presented (Table 2).

Table 2

\section{The results of quality criteria calculation}

\begin{tabular}{|c|c|c|c|c|}
\hline Samples & $\begin{array}{c}\text { Curd } \\
\text { fritters } \\
\text { (control } \\
\text { sample) }\end{array}$ & $\begin{array}{c}\text { Curd fritters } \\
\text { with MPC }\end{array}$ & $\begin{array}{c}\text { Casserole } \\
\text { (control } \\
\text { sample) }\end{array}$ & $\begin{array}{c}\text { Casserole } \\
\text { with MPC }\end{array}$ \\
\hline $\mathrm{S}^{2}$, points & 1618,30 & 1629,64 & 1600,40 & 1620,97 \\
\hline
\end{tabular}

The quality criteria by profiligram in the geometric interpretation determines the optimal variant of the food product with the largest area of the polygon of quality, constructed using normalized dimensionless quality indicators.

The quality criteria were calculated by comparing the $\mathrm{S}$ parameters, followed by a linear approximation of the partial criteria dependencies.

Analyzing the obtained values of individual indicators, the ranking of descriptors by groups of individual indicators was made. According to the results obtained, in the group of curd fritters the priority has the dish «Curd fritters with MPC» by 11.34 points of $\mathrm{S}^{2}$, and in the group of casseroles the priority belongs to the dish «Casserole with MPC» by 20.57 points of $\mathrm{S}^{2}$.

As one can see from the presented graphical profiles of the «quality polygon» criteria, the priority of the samples is preserved.

Conclusion. The results of the conducted researches confirm the feasibility of sensory analysis using and allow reaching the following conclusions:

1. The scientific novelty of the obtained results is to improve the certainty of results of organoleptic evaluation of samples based on descriptors using.

2. The practical significance of the obtained results is manifested in their futher implementation in the work of competition commissions while the evaluation of developed foods with the ability to determine the priority of samples.

3. When determining the priority of samples, it is possible to use the calculation of both the complex quality criteria and the calculation of the quality criteria according to profilograms, as they give identical results.

4. The use of milk-protein co-precipitates in the technology of curd products has a positive impact on the quality of ready dishes.

5. The creation of a system of complex samples evaluation has a lot of prospects for further scientific work. 


\section{REFERENCES}

1. Berketova, L. I., \& Perov, B. V. (2018). The use of sensory analysis in the work of an enterprise of food production. Bulletin of the Voronezh State University of Engineering Technology, 80(1), 146-150.

2. Boyko, T. G. (2010). Requirements for normalization of qualimetric evaluation methods. Measurement Engineering and Metrology, 71, 125-132.

3. Kuzmin, O., Levkun, K., \& Riznyk, A. (2017). Qualimetric assessment of diets. Ukrainian Food Journal, 6(1), 46-60. doi: 10. 24263/2304-974X-2017-6-1-7

4. Kuzmin, O., Pozdniakov, S., Kiiko, V., \& Akimova, L. (2018). Transformational processes the development of economic systems in conditions of globalization: scientific bases, mechanisms, prospects: collective monograph (Vol. 1). Riga: «Landmark» SIA.

5. Koretska, I., \& Zinchenko, V. (2018). Evaluation of research samples by nonlinear quality criteria. World Science in 2018: Results: proceedings of II International scientific conference (pp. 22-26). Morrisville, USA.

6. Deinychenko, G., \& Yudicheva, O. (2014). Sensory analysis of biofortified marinated sweet pepper. East European Journal of Advanced Technology, 2(12), 18-24.

7. Gnitsevich, V., Deinychenko, L., \& Yudina, T. (2017). Technology and biological value of products from milk-protein concentrate. Goods and Markets, 1(23), 139-148. 